\title{
The Effect Of Chief Risk Officer (CRO) On Enterprise Risk Management (ERM) Practices: Evidence From Malaysia
}

\author{
Wan Norhayate Wan Daud, Universiti Darul Iman, Malaysia \\ Ahmad Shukri Yazid, Universiti Darul Iman, Malaysia \\ Hj Mohd Rasid Hussin, Universiti Teknologi MARA, Malaysia
}

\begin{abstract}
This study investigates the level of Enterprise Risk Management (ERM) adoption within the Public Listed Companies (PLCs) in Malaysia and the influence of Chief Risk Officers (CROs) on ERM practices. Included in this particular study is a comprehensive survey on 500 companies from the main board of public listed companies in the Malaysian Bourse. Key findings of this research work reveal that only $42 \%$ of the companies surveyed have completely adopted ERM and based on regression analyses, the 'quality' of CROs has a strong influence on the level of ERM adoption within the PLCs involved in the survey.
\end{abstract}

Keywords: Enterprise Risk Management, Quality of Chief Risk Officers, Corporate Governance

\section{INTRODUCTION}

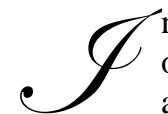

$\mathrm{n}$ this particular century, major corporations inevitably face an array of risks which also include operational risk, market risk, reputational risk and compliance risk, which appear to be receiving much attention to businesses and industries nowadays. In this regard, major corporations of Malaysia were also deeply affected by the poor management of risks during the Financial Crisis of 1997 (Yazid \& Muda, 2006).

Consequently, stakeholders' expectations for senior executives and board of directors to effectively manage all risks that face the company/organization tend to increase. In response to the increasing number and types of risks today's companies/organizations face, leading corporations in the United States (US) such as General Electric (GE), Wal-Mart, Bank of America and IBM, have all begun to adopt Enterprise Risk Management (ERM) for effective management of risks (Drew et al., 2005). Interestingly, things seem to be more positive in Malaysia as the trend among Malaysian companies is towards the implementation of ERM program within the business entities concerned.

It must be mentioned that the ERM, as an increasingly popular concept in this part of the world, is indeed a relatively new term that is catching much today as it is viewed as the ultimate approach to effective Risk Management. Practically, ERM is designed to increase the boards and senior management's ability to oversee the overall portfolio of risks facing an enterprise (Beasley et al., 2006). ERM also provides a significant source of competitive advantage for those who can demonstrate a strong ERM capability and strength (Stoh, 2005).

However, evidence shows that ERM is still not widely practiced in Malaysia. It is rather important to note that scholarly research and empirical evidence in relation to the determinants of such a program is obviously lacking. Equally important to note is that a few reasons have been cited for the companies' non-involvement in ERM program. The reasons include organizational structure that are not conducive to ERM, individuals who do not want to give up their specific responsibilities, a lack of understanding in respect of how to effectively implement ERM and measure the benefits, and also difficulties in measuring risks and correlations across risks within the company (Kleefner et al., 2003). 
Since ERM is a relatively recent activity and has yet to be fully implemented by most companies if not all, it must be highlighted that there has been little academic research about its accomplishments and about the obstacles to further progress. Also, very little has been published about attempts to identify and manage corporate strategic risks while integrating them into a corporate-wide ERM framework (Gates, 2006). While ERM acceptance is on the rise, not all companies are adopting it. Not surprisingly, very little is known about why some companies acknowledge ERM while others do not.

In view of the above, this particular paper therefore aims to fill this research gap by analyzing the management of risks among Malaysian major corporations with a special focus on ERM. Also, this study attempts to investigate whether companies in Malaysia adopt ERM in their workplace, the level of ERM adoption within their business entities and the influence of the quality of CRO on the ERM level of adoption. The paper proceeds as follows: Section 2 presents a literature review and hypothesis development, Section 3 discusses the methodology while Section 4 presents the results and finally the conclusion.

\section{2}

\section{LITERATURE REVIEW AND HYPOTHESIS DEVELOPMENT}

Agency theory, which originates from the fields of financial economics literature, is widely taught in management schools (Ross, 1973; Jensen \& Meckling, 1976; Arrow, 1985). In essence, the theory is an analytic expression of the contractual relationship of two or more parties, in which one party, designated as the principal, engages another party, designated as the agent, to perform some form of services on behalf of the principal (Ross, 1973; Jensen \& Meckling 1976). In return for his/her efforts, the agent usually receives payment of some kind from the principal.

Kaiser (1999) on the other hand, exemplified that agency theory also focuses on the ways principals try to mitigate the problem by selecting certain types of agents and forms of monitoring of their actions by using various amounts and types of positive and negative sanctions. Managers and directors have implicit obligation to ensure that firms are run to meet the interests of shareholders. This is affirmed by Mike (2005) that Risk Management can actually push the performance of the firm in order to enhance shareholders' value. Scholars such as Brealey and Myers (2002), and also Block and Hirt (2000) agree that shareholders' wealth maximization should be the overall goal of every corporate entity.

The agency theory is however related to the focus of this study in view of the fact that ERM can help an organization to achieve its business objectives and ultimately maximize shareholders' value (Bowen et al, 2006; Nocco \& Stulz, 2006). Companies that undertake a risk-based program for shareholder value management typically, can add more to shareholders' value (Bowen et al, 2006). Allayannis and Weston (1998) suggested that active Risk Management does contribute to shareholders' value.

On the whole, Risk Management adds value to individual companies and also supports the overall economic growth by lowering the cost of capital and reducing the uncertainty of commercial activities. Shenkir and Walker (2006) stated that according to the Committee of Sponsoring Organizations of the Treadway Commission (COSO), the ERM model requires executive management commitment for its rigorous implementation. It is strongly suggested that key executives of companies should be eager to make a commitment to ERM because they are ultimately responsible for the overall protection, creation and enhancement of shareholders' value.

\subsection{Enterprise Risk Management (ERM)}

ERM is apparently, the latest name associated for an overall risk management approach to business risks. With regard to the ERM concept, risks are being dealt with on an enterprise-wide basis. As a relatively new field of practice, ERM has quickly taken on a number of different terms. This leads to some confusion as people tend to associate themselves with ERM and it may appear that they are talking about seemingly different things.

Several textbooks and periodicals have introduced and discussed 'corporate risk management', 'business risk management', 'strategic risk management', 'integrated risk management', 'holistic risk management' and 'enterprise-wide risk management' (D'Arcy, 2001). Although each of these terms has a slightly different focus but 
these concepts are similar to, even synonymous with, ERM as they all emphasize a comprehensive view of Risk Management. Such a view is obviously the opposite to the prevalent "silo" approach of managing risks within the entire organization distinctly and the view that Risk Management can be a value-creating exercise, in addition to risk mitigating process.

According to Liebenberg and Hoyt (2003), they articulated that ERM is an integrated approach to managing risks that shifts the focus of the Risk Management function from being primarily defensive to being increasingly offensive and strategic. In this context, it is therefore important to begin by examining the meanings of ERM in order to be aware of the potential uses of ERM and to gradually develop a common understanding of such a term.

In view of the above, it is rather useful to note the definition of ERM as provided by The Committee of Sponsoring Organizations of the Treadway Commission (COSO):

“... a process affected by an entity's board of directors, management and other personnel, applied in a strategy setting and across the enterprise, designed to identify potential events that may affect the entity, and manage risk to be within its risk appetite, to provide reasonable assurance regarding the achievement of entity goal."

Based on the above definition of ERM reflects certain fundamental concepts whereby it is:

- $\quad$ "A process, ongoing and flowing through an entity;

- $\quad$ Effected by people at every level of an organization;

- $\quad$ Applied in strategy setting;

- $\quad$ Applied across the enterprise, at every level and unit and includes taking an entity (level portfolio view of risk);

- $\quad$ Designed to identify potential events that, if they occur, will affect the entity and to manage risk within its risk appetite;

- $\quad$ Able to provide reasonable assurance to an entity's management and board of directors;

- Geared to achievement of objective in one or more separate but overlapping categories" (Flaherty et al., 2006).

A number of ERM frameworks are currently being used. They include: The Combined Code and Turnbull Guidance, King 11 Report, A Risk Management Standard by the Federation of European Risk Management (FERMA), Australia/New Zealand Standard 4360-Risk Management, COSO's Enterprise Risk ManagementIntegrated Framework, The Institute of Management Accountants' (IMA) "A Global Perspective on Assessing Internal Control over Financing Reporting" (ICoFR), Basel 1l, and also the Standard and Poor's and ERM. Although they are different in name, industry and region, nevertheless, they all share a common theme: the identification, prioritization and quantification of risks in order to help corporations effectively manage their exposure.

In this regard however, one of the most popular frameworks being implemented is the Committee of Sponsoring Organizations of the Treadway Commission (COSO) (Bohn \& Kemp, 2006). The foundation for the ERM methodology was based in COSO's 1992 Internal Control - Integrated Framework, a publication that formulated a uniform approach to managing internal control system (Bowen et al. (2006). COSO's ERM Integrated Framework expended the approach by integrating these control throughout an enterprise. It provides Risk Management architecture in terms of eight (8) components to be considered under each of the four (4) categories of objectives. Therefore, each level of the organization applies the eight (8) components of ERM to the following four (4) categories of objectives concerned. A particular objective may be classified into one or more categories. Thus, the classification may delineate the objective into multiple lines of authority.

\subsection{Quality of Chief Risk Officers (CRO) and Enterprise Risk Management (ERM)}

It is argued that companies choosing to adopt the ERM strategy need a person or group of persons responsible for the coordination of the entire ERM program, and also the communication of goals and results to the Board of Directors concerned. Liebenberg and Hoyt (2003) suggested that some commentators favor the use of 
ERM committee over the use of a single individual as the person/party responsible for leading the ERM function within the entire corporate entity. Others argue that it is better to manage such risks via a single organizational unit that bears direct responsibility for supervising the entire process rather than via a committee or group of committees.

The COSO Report (2004) on ERM defines the role of the CROs as one working with other managers in establishing effective Risk Management and one who has full responsibility for monitoring progress and also for assisting other managers in reporting relevant risk information up, down and across the entire entity. The position of CRO also requires a person instilled with certain requisite qualities. It is argued that the two (2) key qualities that need to be the character of CRO are strong advocate of teamwork and communication.

Rosa (2006) postulated that qualities of a successful CRO are well developed risk-consciousness, knowledge of main business processes, current education in Risk Management curriculum, communication skills that include the ability to work closely with individuals at all levels, facilitation skills including appropriate skills in insurance, finance and accounting.

In addition, COSO (2004) proposed that a quality CRO is a person who needs to have the following attributes: ability to serve as an advisor to the CEO, has in-depth industry knowledge and experience, integrity and credibility to communicate with business leaders, regulators and other stakeholders, equipped with comprehensive Risk Management expertise and experience, excellence in managerial skills and able to motivate and lead a diverse group of professionals with varying background, quick and strategic thinker, strong negotiation skills and also the ability to effectively formulate the Risk Management policy to meet strategic objectives.

\subsection{Theoretical Framework}

The independent variable (IV) of this study is Quality of the Chief Risk Officer (CRO) and the Level of ERM Adoption is the dependent variable (DV).

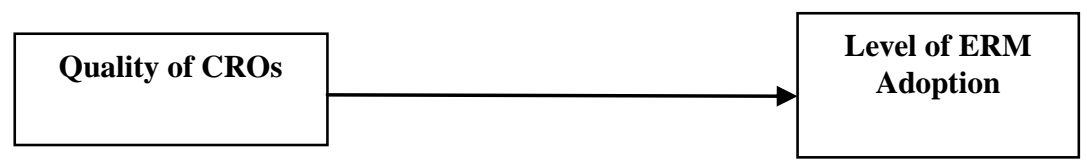

Figure 1

Conceptualization of the relationship between Quality of CRO and Level of ERM Adoption

\subsection{Hypotheses Development}

The first main objective is to answer the question on what is the Level of ERM adoption in major companies in Malaysia. In addition, the study attempts to examine the factor that influences the Quality of CRO and the Level of ERM adoption by the companies concerned.

\subsubsection{Level of ERM Adoption}

Kleffner et al. (2003) acquired data from a mail survey as well as telephone interviews sent to the Canadian Risk and Insurance Management Society members Board of Directors and ERM. The result indicates that 31\% of the sample had adopted ERM and the reasons for adopting ERM include the influence of the risk manager (61\%), encouragement from the board of directors (51\%) and compliance with Toronto Stock Exchange (TSE) guidelines $(37 \%)$.

It is therefore necessary and timely to find out the scenario in Malaysia too. To further examine this particular area, this research work thus focuses on the Quality of CRO that might influence the level of ERM adoption by major corporations in Malaysia. 


\subsubsection{Quality of Chief Risk Officer (CRO) and Level of ERM Adoption}

As mentioned earlier, the announcement of a CRO's appointment is an early signal or indication that the company is establishing an ERM program. The CRO is therefore responsible for ERM implementation and coordination of ERM within the entire organization. According to Liebenberg and Hoyt (2003), many researchers are relying on survey data for a signal on the existence of ERM program.

A survey conducted by Tillinghast-Towers Perrin (2002) suggests that the company views the CROs and ERM committee as complementary rather than alternative management bodies because the companies do not publicly announce the formation or existence of an ERM committee. Thus, the appointment of the CRO was therefore used as a signal in relation to the establishment of the ERM program.

The Economist Intelligence Unit (EIU) (2005) also reported that many organizations appoint a member of the senior executive team (often referred to as the CRO) to oversee the ERM's process. In addition, many researchers concluded that the presence of a CRO is associated with a greater stage of ERM adoption (Beasley et al., 2005).

Based on the above literature, the study therefore hypothesizes that:

H1: There is a positive relationship between Quality of CRO and level of ERM adoption

\section{METHODOLOGY}

This particular study includes a survey comprising 500 major corporations which are listed under the main board of the Malaysian Bourse. Only seven (7) industries namely, construction, consumer product, industrial product, plantation, properties, trading and services, and also construction were chosen. Reason for such a selection is that the researcher is highly interested in conducting an industry survey due to many researchers like Beasley (2005b); Liebenberg et al., (2003) and Pagach and Warr (2007) all of whom have affirmed the evidence which financial industry have already been involved in ERM.

A stratified random sampling technique was used to obtain the number of samples for this study.

Below is the summary of the sample of companies for this study:

Table 1

Sample of Companies

\begin{tabular}{|l|c|c|c|}
\hline \multicolumn{1}{|c|}{ Type of Industry } & $\begin{array}{c}\text { Number of Companies } \\
\text { (population) }\end{array}$ & $\begin{array}{c}\text { Companies Selected } \\
\text { (sampling frame) }\end{array}$ & Companies Participated \\
\hline Technology & 18 & 15 & 9 \\
Industrial Product & 156 & 134 & 8 \\
Property & 94 & 81 & 16 \\
Consumer Product & 87 & 75 & 6 \\
Plantation & 44 & 37 & 20 \\
Trade and Services & 141 & 121 & 11 \\
Construction & 44 & 37 & $\mathbf{8 9}$ \\
\hline Total & $\mathbf{5 8 4}$ & $\mathbf{5 0 0}$ & \\
\hline
\end{tabular}

The mail questionnaires are being posted together with self-returned envelope (with postage paid for) to ensure a high response rate. The questionnaires were addressed to the company's Chief Executive Officer (CEO)/Board of Directors (BOD). The usable sample that can be used in the study is 89 whereas 39 samples were rejected due to questionnaires returned to researcher left unanswered and incomplete. 


\subsection{Measurement of the variables}

Five hundred questionnaires were distributed to the companies sampled in the survey. The questionnaires were adapted from the COSO (2004) framework (Beasley et al., 2005b; Bohn \& Kemp, 2006; Gates, 2006 and Shenkir \& Walker, 2006). The purpose of this study is to identify the levels of ERM adoption by the companies and whether the result indicates complete application of ERM or otherwise. The result is expected to reveal the level of ERM adoption by these companies.

The independent variable in this study is the factor that influences the level of ERM adoption. It relates to the Quality of Chief Risk Officer (CRO). The Quality of CRO characteristics towards ERM in this study is measured by examining seven (7) equally important elements: (1) develops integrated procedures to report on major risks to the board member CRO (2) regularly meets with the senior executives to promote embedding Risk Management into daily activities (3) develops a standardized risk information model to the firm (4) maintains a cost benefit focus on ERM (5) ensures employees are educated about Risk Management (6) works with unit leaders to ensure that risk identification is included in the overall business plans (7) works with unit leaders to ensure the most significant risk compliance with the organization's standards.

Companies' representatives were asked five questions that relate to the identification of CRO. The Companies' representatives were requested to tick based on the relevant answers most suited to them. They were also asked seven (7) specific duties with regard to the practice of CRO in the organization. They are requested to rate on a scale of 1 (strongly disagree) to 5 (strongly agree) for each of the seven (7) statements.

Table 2

Summary on number of questionnaires for the Mail Survey

\begin{tabular}{|l|c|c|}
\hline \multicolumn{1}{|c|}{ Measurements } & Number of items in the Questionnaires & $\begin{array}{c}\text { Questions adapted/ adopted from } \\
\text { Previous Study }\end{array}$ \\
\hline Section A: Demographic Information & Qtn No.1 to Qtn No. 11 & \\
\hline (Dependent Variable) & & \\
Section B: Level of ERM Adoption & Qtn No.1 (2006) \\
(1) Complete ERM in Place & & Beasley et al., (2005b) \\
(2) Partial ERM in Place & & \\
(3) Planning to implement ERM & & \\
(4) Investigating to adopt ERM & & \\
(5) No plan Exist & & \\
Section C: Quality of CRO & Qtn No.2 to & \\
(1) Identifications of CRO & Qtn No.6 & COSO, (2004) \\
(2) CRO specific duties & Qtn No.7 & \\
\hline
\end{tabular}

\section{$4 \quad$ RESULTS}

The Level of ERM Adoption and the Quality of CROs were measured by COSO (2004) ERM framework. The Quality of CROs was measured by looking at their specific tasks in ERM implementation.

The analysis of data includes Descriptive Analysis, Factors Analysis, Reliability Test and Logistic Regression. The Descriptive Analysis was performed to provide the general background of respondents and organizations that participate in this study. Empirically, the result of the study proved that ERM practice amongst Malaysian companies is still at an early stage. A total of 43 percent of the respondents surveyed, affirmed that they have completely adopted ERM, 38 percent partially adopted ERM, five (5) percent are planning to adopt ERM while 14 percent are still investigating to adopt ERM (Table 4). 
Therefore, it could be deduced that the level of ERM implementation is still at the early stage. Given the small number respondents, the level of ERM adoption was reconstructed into two (2) namely, complete ERM in place and partial ERM in place. The complete ERM in place is considered as 'complete ERM in place' while partial ERM in place, planning to implement ERM and investigating to adopt ERM are considered as "partial ERM in place.' No plan exist is omitted due to the number respondents for this level is negligible and are therefore considered as non-adopters. The overall results therefore show those 37 organizations (or 43 percent) with complete ERM in place and 49 organizations (or 57 percent) with partial implementation of ERM within their organizations.

Table 3

Level of ERM Adoption Status

\begin{tabular}{lccc}
\hline \multicolumn{1}{c}{ Level of ERM Adoption } & Frequency $(\mathbf{N}=\mathbf{8 6})$ & Percentage & ERM Status \\
\hline Complete ERM in place & 37 & 0.43 & Complete \\
\hline Partial ERM in place & 33 & 0.38 & \\
Planning to implement ERM & 4 & 0.05 & Partial \\
Investigating to adopt ERM & 12 & 0.14 & \\
\hline
\end{tabular}

First of all, the study employs factor analysis for quality Chief Risk Officer (CRO). The results indicated that the Kaiser - Meyer -Olkin (KMO) measure of sampling adequacy at 0.76, indicated that the items were interrelated and they shared common factors (Table 5). Bartlett's test of sphericity was also found to be significant (Approx. Chi-Square $=240.302, \mathrm{p}<.001$ ) indicating the significance of the correlation matrix and thus the suitability for factor analysis.

The individual MSA values ranged from .54 to .85 , indicating that the data matrix was suitable to be factor analyzed. Results of the varimax rotated analysis indicated the existence of one significant component with eigenvalues 3.59 that explained $51.22 \%$ of the total variances. Therefore, all the measurement done to Quality of CRO is accepted.

Furthermore, findings of this study affirmed that the reliability of measure is above the minimum acceptable reliability with Cronbach's alpha 0.833 . The Logistic Regression was also performed to predict and explain the two group categorical variable of this study (complete ERM in place/partial ERM in place). The result shows that the variable (quality of CRO) was statistically significant in relation to the adoption of ERM.

Table 4

Factor Analysis for Quality of Chief Risk Officer (CRO)

\begin{tabular}{lc}
\hline & Component 1 \\
\hline CRO ensures employees are educated about Risk Management & .849 \\
CRO regularly meets with the senior executives to promote embedding Risk Management into daily & .764 \\
activities & .756 \\
CRO works with unit leaders to ensure the most significant risk compliance with the organization's & .721 \\
standards & .694 \\
CRO works with unit leaders to ensure that risk identification is included in the business plans & .649 \\
CRO develops a standardized risk information model to the firm & .537 \\
CRO maintains a cost benefit focus on ERM & $\mathbf{3 . 5 9}$ \\
& $\mathbf{5 1 . 2 1 6 \%}$ \\
Eigenvalues & $\mathbf{0 . 7 6 2}$ \\
KMotal Variances Explained &
\end{tabular}

Binary Logistic Regression was used to explain the relationship between independent variable (Quality of CRO) on the Level of ERM Adoption. Key findings show that the Omnibus Test of model coefficients is statistically significant because the p-value is less than .00 whereby this chi-square statistic is 16.809 (Table 6). 
Table 5

Omnibus Tests of Model Coefficients

\begin{tabular}{lcccc}
\hline & & Chi-square & Df & Sig. \\
\hline Step 1 & Step & 16.809 & 2 & .000 \\
\cline { 2 - 5 } & Block & 16.809 & 2 & .000 \\
\cline { 2 - 5 } & Model & 16.809 & 2 & .000 \\
\hline
\end{tabular}

The -2 likelihood for this study is 100.73 and the value of Nagelkerke- $\mathrm{R}^{2}$ of 0.238 for this Logistic Regression, suggested that the accuracy of the factors influencing the level of ERM can be explained by the predictor variable under study at $23.8 \%$ that enlighten a well fitting model (Table 7 ).

Table 6

Model Summary

\begin{tabular}{cccc}
\hline Step & $\mathbf{- 2}$ Log likelihood & Cox \& Snell R Square & Nagelkerke R Square \\
\hline 1 & $100.732(a)$ & .178 & .238 \\
\hline
\end{tabular}

The Hosmer and Lemeshow test provides the chi-square value of 4.070 with $\mathrm{p}=0.772$ and it indicates that the Binary Logistic Model fits well with the data (Table 8), hence the validity of the model tested.

Table 7

Hosmer and Lemeshow Test

\begin{tabular}{ccccc}
\hline Step & Chi-square & Df & Sig. \\
\hline 1 & 4.070 & 7 & .772 & \\
\hline
\end{tabular}

In addition, the summary of the fitted Binary Logistic Regression Model is given based on the variables in the Equation which signifies that the predictor variable, which is the quality of Chief Risk Officer, does influence the level of ERM adoption with the sig. value are 0.003. After using stepwise logistic regression, the result reveals that the quality of Chief Risk Officer has a sig. value of 0.03 . Hypothesis 1 is therefore supported.

H1: There is positive relationship between quality of CRO and level of ERM adoption

\section{CONCLUSION}

As a conclusion, the study confirms that some of the major corporations in Malaysia had already adopted the ERM framework. However, the stage of adoption can still be considered as the early stage. This survey incorporated in this particular study also reveals that the Quality of CRO significantly influences the organization to practice ERM.

Based on the limitations of this study, future researchers on similar research topic are recommended to make an improvement in certain areas. It is important to note that there is a need to investigate the organizational performance after applying ERM. It must also be emphasized that a study of more than one (1) year would be necessary. Such a period would provide the avenue to examine a trend or pattern of performance for those companies/organizations that applied ERM.

It is strongly suggested that the research approach could possibly utilize a qualitative research method such as the in-depth interviews, case studies or in combination with survey questionnaires. In addition, additional variables could be included to create a new framework. Finally, future researchers may also think of other variable(s) that could mediate the relationship of the company to perform better or more effectively after the implementation of ERM. 


\section{REFERENCES}

1. Allayannis, G. and Weston, J. (1998). The use of foreign exchange derivatives and firm market value. Working Paper, University of Virginia.

2. Arrow, K. (1985). The Economics of agency. In Pratt. J. \& Zeckhauser, R. (eds.) principal and Agents: the structure of Business Boston: Harvard Business School Press, 37-51.

3. Beasley, M. S., Clune, R. \& Hermanson, D.R. (2005). Enterprise Risk Management: An Empirical Analysis of Factors Associated with the Extent of Implementation. Journal of Accounting and Public Policy.24 (6), 521-531.

4. Beasley, M. S., Clune R., Hermanson D.R., (2006). The impact of Enterprise Risk Management on the Internal Audit Function. Strategic Finance, 1-26.

5. Berghe L.A.A V. and Levrau A. (2004). Evaluating Board of Directors: What constitutes a good corporate board?. Blackwell Publishing Ltd.12 (4), 461-478.

6. Block, S.B. and Hirt, G.A (2000). Foundations of financial management. $9^{\text {th }}$ edition, Pitman publishing, London.

7. Bowen, J.K., Cassel, R., Dickson, K., Fleet, M., Ingram, D., (2006). Enterprise Risk Management Specialty Guide (ERMSG).

8. Bohn, C. and Kemp, B., (2006). Enterprise Risk Management Quantification - An Opportunity. AON, 1-12.

9. Brealey, R.A. and Myers S.c (2002) Principles of corporate finance, $7^{\text {th }}$ edition, MacGraw-Hill/Irwin, London.

10. Cole, J.W, McWilliams, V.B and Sen, N. (2001). An examination of the relationship of Governance Mechanisms to Performance. Journal of Management. 27 (23-50).

11. Committee of Sponsoring Organizations (COSO), (2004). Enterprise Risk Management - Integrated Framework. COSO, New York.

12. Conyon, M.J. and Peck, S.I. (1998). Board size and corporate performance: Evidence from European countries. The European journal of finance. 4, 291-304.

13. Dalton, D.R., Daily, C.M., Johnson J.L., Ellstrand, A.E. (1999). Number of Directors and Financial Performance: A Meta Analysis. Academy of Management Journal 42 (6), 674-686.

14. D'Arcy, S.P. (2001). Enterprise Risk Management. Journal of Risk Management of Korea 12.1.

15. Drew, S.A., Kelley, P.C. , Kendrick, T. (2005). CLASS: Five Elements of Corporate Governance to Manage Strategic Risk. ElsevierInc.doi:10.1016/i. bushor.2005.7.001.

16. Economist Intelligence Unit Limited and MMC Enterprise Risk, Inc (2001). Enterprise Risk Management: Implementing New Solutions (New York).

17. Fama, E.F. and Jensen, M.C. (1983). Agency problems and residual claims. Journal of law and economics. 26, 327-49.

18. Farell, J. (2004). Internal controls and managing Enterprise-Wide Risks. The CPA Journal. 74 (8) 11-12.

19. Gates, S. Nantes A. (2006). Uncorporating Strategic Risk into Risk Management: A Survey of Current Corporate Practice. Journal of Applied Corporate Finance. 81-90.

20. Greenhill J. (2007). The Board of Directors in Risk Governance. Insurance and Risk Management. 74 (2), 187-200.

21. Haron, H, Ibrahim, D.A., Ismail, I., Chun Hoo, Q., Kader Ali, N, N., Zainuddin, Y., Nasaruddin, E. (2006). Governance, ethnics and corporate responsibility of public listed companies in Malaysia. Unpublished Working Paper, Universiti Sains Malaysia.

22. Jensen, M.C., and W. Meckling, (1976). Theory of the Firm, Managerial Behavior, Agency Costs and Ownership Structure. Journal of Financial Economics. 3, 305-360.

23. Kaiser, E (1999). Comapring varieties of Agency Theory in economics, Political Science and Sociology: An Illustration from state policy implementation. Society Theory. 17 (2) 146-170.

24. Kleffner, A., Lee, R., McGannon, B., (2003). The Effect of Corporate Governance on the Use of Enterprise Risk Management: Evidence from Canada. Risk Management and Insurance Review 6 (1), 53-73.

25. Liebenberg, A. and Hoyt, R., (2003) The Determinants of Enterprise Risk Management: Evidence From the Appointment of Chief Risk Officers. Risk Management and Insurance Review 6 (1),37-52.

26. Malaysia Institute of Corporate Governance (MICG) (2001). Malaysia Code on Corporate Governance.

27. Mikes, A. (2005) Enterprise Risk Management in Action. Discussion Paper Published by the Center for analysis of Risk and Regulation at London School of Economics and Political Science. 
28. Moody M. J., (2007). Pressure from the BOD. Rough Notes. 150 (9) ABI/INFORM Global.

29. Moody M. J., (2007). ERM: Are Directors on Board?. Rough Notes. 150 (5) ABI/INFORM Global.

30. Nocco, B.W. and Stulz, R.M. (2006). Enterprise Risk Management: Theory and Practice. Journal of Applied Corporate Finance. 18 (4) 1-8.

31. Pagach, D. and Warr, R. (2007). An Empirical Investigation of the Characteristics of Firms Adopting Enterprise Risk Management. North Corolina State University Working paper.

32. Rosa de la S., (2006). Board influences cultivating the best board. Accountancy SA.

33. Ross, S. A (1973). The Economic Theory of Agency: The Principal's problem. American Economic Review. 63 (2) 134-139.

34. Shenkir, W.G and Walker, P.L (2006). Enterprise Risk Management: Framework, Elements and Integration. Institute of Management Accountant.

35. Stoh, P.J. (2005). Enterprise Risk Management at united Health Group. Strategic Finance. 87(7) 26-35.

36. Tillinghast - Towers Perrin, (2002). Enterprise Risk Management in the Insurance Industry - 2002 Benchmarking Survey Report. http//www.tillinghast.com/tillinghast/publications/reports/ERM_Insur_Ind_2002_benchmark_Survey/ERM 2002_all.pdf.

37. Uzun H., Szewezyk S.H., Varma R. (2004). Board composition and corporate fraud. Financial Analysts Journal. 60 (3), 33-43.

38. Yazid, A.S. and Muda, M.S. (2006). The Role of Foreign Exchange Risk Management in Malaysia. Irish Journal of Management, Dublin, 26 (2), 45.

39. Yermack, D (1996). Higher market valuation of companies with a small board of directors. Journal of Financial Economics, Vol. 40 (2) (185-221). 